\title{
Reflexos da formação acadêmica na docência universitária
}

\author{
Reflections of the academic training in the university teaching
}

Kelly Roberta Mazzutti Lübeck kellyrobertaml@gmail.com

\begin{abstract}
Resumo
Neste artigo, abordarei alguns dos reflexos da formação acadêmica nas escolhas e nas tomadas de decisões de professores universitários frente aos desafios da profissão docente a nível superior. Como método investigativo utilizarei a investigação pela própria prática por ser considerada uma importante ferramenta que contribui para esclarecer problemas da prática e propor soluções. Assim, através deste relato de experiência, vou listar determinados motivos que levam docentes de formação puramente matemática a buscar respostas aos anseios da profissão em atividades mais voltadas à Educação Matemática.
\end{abstract}

Palavras-Chave: Formação acadêmica; Matemática; Docência no Ensino Superior.

\begin{abstract}
In this article, I will discuss some of the reflections of the academic training in the choices and in the decision of the university teachers front to the challenges of the teaching profession at a higher level. As investigative method I will use research by the practice because it is considered an important tool that helps to clarify the practical problems and propose solutions. Thus, through this experience report, I will list some reasons why teachers of purely mathematical training will seek answers to the yearnings of the profession in activities geared to mathematics education.
\end{abstract}

Keywords: Education; Mathematics; Teaching in Higher Education.

\section{Introdução}

O caminho para a profissão de docente universitário é longo, requer anos de estudos e, por vezes, é atribulado. Pressupõe que começa cedo, antes mesmo da sua escolha explícita, pelo que muitos designam de vocação. Logo, começa com a vontade de ser professor. Vontade esta que não associa a docência como uma vocação no sentido clássico, “[...] como um chamamento espiritual, [mas como] uma atividade que tem essa natureza de repartir, de se preparar, de trabalhar o tempo todo com o futuro" (CORTELLA, 2014, p. 120).

No meu caso, tal escolha foi motivada pelo desejo de ensinar, de compartilhar. Lembro-me que, ainda criança, já riscava com giz as paredes da casa de meus pais, brincando com meus irmãos de escola, de sala de aula, de ser professor, e minha mãe via nisto mais do que uma parede suja e rabiscada, via a possibilidade de um de seus filhos ingressar no magistério, opção que sempre lhe agradou muito. 
Deste modo, terminado o ensino fundamental, optei por estudar na única escola de minha cidade que oferecia o curso a nível profissionalizante de magistério, que nos três primeiros anos trabalhava com as disciplinas didáticas e pedagógicas, e permitiam obter a equivalência do ensino médio, e no quarto ano realizavam-se os estágios curriculares, imprescindíveis para conclusão e total habilitação para o exercício da função. Como forma de ampliar as chances de estudar no ensino superior, fiz o vestibular ainda no terceiro ano do magistério recebendo, por fim, somente o certificado de conclusão do ensino médio.

A escolha pela área da docência se deu no dia de preencher o cartão da inscrição no vestibular e só se confirmou durante os anos em que cursava a graduação em matemática, curso de licenciatura plena, mas com uma forte característica de bacharelado. Naquele momento, a matemática, com todos os seus desafios, proposições, corolários, demonstrações, etc., me encantou. Fiquei deslumbrada pelas suas possibilidades teóricas, pela aplicação nas outras várias ciências, pela forma como explica tanto os fenômenos do nosso cotidiano quanto os aquém das crendices populares, e minha graduação só reforçou a ideia de buscar mais conhecimentos sobre o que gostamos de chamar de "Rainha das Ciências".

Portanto, motivada pelas observações sobre os desígnios que norteiam a escolha de uma carreira profissional, na sequência deste artigo, irei tecer comentários sobre a preferência de uma área (Matemática Pura) e a formação do perfil docente envolvido nela, bem como procuro apontar os motivos que levam docentes de formação puramente matemática a buscar respostas aos anseios da profissão em atividades mais voltadas à Educação Matemática. Recoro, para tanto, ao método da investigação pela própria prática, segundo o qual PONTE (2004, p. 4) coloca que "a característica definidora desta forma particular de investigação refere-se apenas ao facto que o investigador tem uma relação muito particular com o objecto de estudo - ele estuda não um objecto qualquer mas um certo aspecto de sua prática profissional." Além disso, Ponte (2004, p.4) esclarece o que entende por investigação, ou seja,

a identificação de um problema relevante - teórico ou prático - para o qual se procura, de forma metódica, uma resposta conveniente. A investigação só termina quando foi comunicada a um grupo para o qual ela faz sentido, discutida e validada no seu seio.

Dessa forma, o autor reitera as três condições básicas apresentadas por Beillerot (2001) que definem um trabalho investigativo: i) produção de novos saberes; ii) estudo metódico e iii) publicidade dos resultados.

É interessante destacar que este trabalho se pauta nas experiências e inquietações vivenciadas ao longo da minha formação e atuação docente e no conhecimento de programas 
de graduação e pós-graduação obtidos pela troca de informações com profissionais de várias instituições públicas de ensino superior. Cabe enfatizar que

\begin{abstract}
a investigação dos profissionais sobre sua própria prática pode ser importante por várias razões. Antes de mais, ela contribui para o esclarecimento e resolução de problemas; além disso, proporciona o desenvolvimento profissional dos respectivos actores e ajuda a melhorar as organizações em que eles se inserem [...] [e] tem como finalidade contribuir para clarificar os problemas da prática e procurar soluções. (PONTE, 2004, p. 2).
\end{abstract}

Portanto, tal método propicia uma investigação sobre os procedimentos adotados por um indivíduo (ou um grupo) em uma determinada prática, permitindo alcançar reflexões que motivam reavaliar seus processos na busca constante por melhorias.

\title{
A escolha de uma área e suas implicações
}

$\mathrm{Na}$ conclusão de uma licenciatura surgem várias questões: "Como enfrento o mercado de trabalho? Qual o nível de ensino que mais me identifico? Devo continuar a estudar ou ganhar experiência profissional?" Elas estão associadas, de certa forma, a insegurança, incerteza no futuro, pois se concluí a primeira etapa do desenvolvimento profissional e espera-se o retorno deste período, começando pelas cobranças da família e da sociedade.

Neste momento, acredito que surgem os primeiros reflexos do tipo de formação acadêmica oferecido para o graduando. Quando um curso de licenciatura privilegia na sua concepção a matemática mais formal, técnica, com forte inserção de disciplinas mais voltadas para o bacharelado, o licenciando tende a optar pela continuidade de seus estudos. Ou porque se identificou com a Matemática Pura (ou Aplicada), pois teve na sua formação uma ênfase nesta linha e pretende continuar seus estudos nesta área, ou buscará na pós-graduação em Educação Matemática as respostas para as questões didáticos pedagógicas envolvidas no ensino/aprendizagem da matemática que, num certo sentido, lhe foram negligenciadas na graduação.

Os que optam por continuar seus estudos na área da Matemática Pura vão se deparar com o aprofundamento dos conteúdos trabalhados na graduação, revisando e aperfeiçoando os fundamentos de várias disciplinas técnicas. Além disso, no geral, os cursos de mestrado (e posteriormente doutorado) oferecem outros créditos que permitem ao acadêmico adquirir uma compreensão global da matemática, perfazendo um pouco das suas grandes áreas, como análise, equações diferenciais, álgebra, topologia e geometria.

Depois de tomar conhecimento desta matemática, cabe ao graduado decidir pela sua área de formação específica e definir, juntamente com seu futuro orientador, um tema para seus estudos. O projeto de pesquisa é definido, a menos de poucas exceções, em conjunto com 
o orientador, sendo este o propositor da ideia, do objeto a ser estudado, dentro de sua área de interesse.

Os cursos de pós-graduação em Matemática, na maioria dos casos, não oferecem créditos de metodologia científica ou trabalham em seu corpo estrutural os aspectos de uma pesquisa, as metodologias para formulação e validação de resultados. Esta postura se dá, pois a ênfase da proposta curricular está amparada no aprofundamento dos conteúdos de matemática e na formulação de artigos científicos. Também, pela característica das pesquisas, que se pautam, necessariamente, em referências bibliográficas, os trabalhos gerados nos mestrados são leituras e/ou releituras de temáticas já discutidas.

Isto se deve, pois a proposição de 'novas' matemáticas (da criação inédita) requer o conhecimento de muitos conteúdos já trabalhados e, somente depois de superados todos os pormenores desta gama de trabalhos já apresentados é que o estudante/pesquisador poderá propor algo novo e, a depender da linha de pesquisa, isto pode ser um trabalho de anos de investigação.

Assim, se o graduado não estudou tais métodos em sua graduação, este acaba por não refletir sobre toda a técnica de investigação científica, enfatizando na pesquisa a busca pelos resultados, ou seja, com uma visão restrita do processo.

Esta falta de desenvoltura na formulação de projetos dificulta o trabalho docente frente aos vários órgãos de fomento com os quais o profissional deve trabalhar. Além do mais, as universidades executam suas rotinas de atividades pautadas em projetos: de extensão, de pesquisa, de iniciação científica, de monitoria, etc. Deste modo, cabe ao professor procurar subsídios que o auxiliam nesta questão.

Por outro lado, devido aos anos de estudo e trato com a matemática de nível superior, uma das vantagens no perfil deste profissional está ligada ao rigor na escrita matemática, no uso das simbologias e na forma como apresenta as proposições e resultados a serem analisados - enfatizando as estruturas próprias da matemática, características que facilitam o aprendizado desta disciplina e que, em muitos casos, são transmitidas no dia a dia de seu trabalho junto ao curso de licenciatura. Até porque, conforme Magossi e Poletti (2012),

Caracterizar e verbalizar que a matemática pode ser vista como uma linguagem composta de estruturas e objetos e não, simplesmente, como uma linguagem adaptada a resolver problemas do dia-a-dia, pode motivar o desenvolvimento da intuição matemática que advém, não só da matemática vista como sendo útil à resolução de problemas práticos do dia-a-dia, mas também de sua visão intrínseca como estruturas e objetos, na busca contínua por padrões. (p. 11). 
Outrossim, a precisão na linguagem matemática promove a compreensão da proposição que será analisada. É dever do professor de matemática apresentá-la de forma clara, coesa, facilitando o entendimento dos alunos. Neste sentido, o emprego adequado da simbologia pode conduzir a esclarecimentos sobre o tema abordado, bem como levar o aluno a estabelecer conexões com outros assuntos.

\begin{abstract}
As notações representam concepções matemáticas que são "transmitidas" aos estudantes que, por sua vez, são utilizadas para formação de sua própria concepção em uma estrutura mental de representação dessas concepções. $\mathrm{O}$ cuidado com o uso de um certo sistema notacional deve ser considerado, a fim de que se tenha uma adequação no nível de sua elaboração e utilização. (BRANDEMBERG, 2010, p. $135)$.
\end{abstract}

Outro aspecto do profissional que estuda Matemática Pura é que ele possui uma visão geral de toda a matemática básica, o que lhe possibilita, se for de seu interesse, realizar articulações entre a matemática escolar e os conteúdos do ensino superior e que, portanto, pode fazer uso de tais habilidades para melhor preparar o licenciando na busca por diferentes métodos na resolução dos problemas.

Cabe grifar, aqui, que estas articulações nem sempre são fáceis de estabelecer, seja pela complexidade da disciplina ou por sua natureza, que descreve generalizações de processos matemáticos. Entretanto, ações indicam que este movimento de aproximação/estreitamento entre a matemática acadêmica e a formação do licenciado vem se firmando. Exemplo disso são os livros de Ávila (2006), Morais Filho (2007), Ferreira (2010) e Brandemberg (2010).

Saliento, entretanto, que ao mencionar acima "precisão matemática" não estou me referindo ao excesso de formalismo e uso exagerado de notações e fórmulas desmedidas. Ao contrário, trata-se de uma matemática exposta de forma simples, sem rodeios ou macetes, uma matemática que oferece explicações e entendimento dos fatos e situações.

Como aspecto negativo do perfil deste profissional, ou seja, uma desvantagem deste docente é uma postura mais arraigada às formas tradicionais de ensino, menos aberto a mudanças, baseando sua metodologia de trabalho em exemplos por ele vivenciados. Acredito que isto se deve pela própria estruturação da ciência matemática, que fundamenta suas argumentações, desde seus primórdios, em sistemas lógico/dedutivos. De fato, como exemplo colocamos a passagem da introdução de Bicudo (apud EUCLIDES, 2009, p. 15) informando que, "mesmo que o material coberto por Euclides possa ser considerado elementar na sua maior parte, o modo como ele o apresenta estabeleceu o padrão por mais de dois mil anos." 
Além disso, tal profissional tende a ser mais intolerante com os erros dos alunos, mais apegado ao apreço da matemática pela matemática, pois muitas das pesquisas realizadas em Matemática Pura não possuem aplicação imediata, logo retoma-se este apego pela forma estética desta ciência. Tal postura pode tolher a criatividade dos alunos, impedindo que eles relacionem a técnica da resolução à análise dos problemas. De mais a mais, "uma apresentação do conhecimento matemático absolutizado em sua forma compacta, abstrata e formal [...] pode reforçar certos tipos de dificuldades que o professor vai eventualmente encontrar em sua prática educativa". (MOREIRA; DAVID, 2005, p. 103).

Contudo, há que se observar (pela sua própria evolução histórica) que a matemática só alcançou o atual desenvolvimento de suas áreas de pesquisa devido ao aprimoramento de seu sistema simbólico, ou seja, sua forma de representação. Outrossim, todos devem ter acesso a uma sólida base científica, ultrapassando o conhecimento pragmático e, para tanto, no caso da matemática, necessita-se do formalismo conceitual, da matemática tradicional e não arcaica (cf. CORTELLA, 2014). Portanto, cabe ao professor, pautado em seus conhecimentos e no conhecimento de sua turma, determinar a melhor forma de transmitir determinados conteúdos.

Note que estes apontamentos são meras observações sobre possíveis perfis dos profissionais ligados a esta linha, caracterizações baseadas no tipo de atividade praticada na maioria dos programas de pós-graduação em Matemática Pura, até porque, como docente universitária com formação nesta área, sei das dificuldades e das restrições legais na formulação dos programas. Ademais, é justamente no espaço das pós-graduações que estão os ambientes para a realização de pesquisas voltadas para o "criar matemática de ponta", "a matemática pela matemática", uma vez que, conforme Peter Hilton (apud EUCLIDES, 2009, p.15), "a matemática genuína constitui uma das finas expressões do pensamento humano", de onde ressalto a importância de tais programas para a efetivação da própria matemática como ciência investigativa.

\section{Os desafios da profissão frente à formação docente}

Para o docente universitário com formação em Matemática Pura, a sala de aula de uma universidade não apresenta dificuldades com relação aos seus créditos/disciplinas propostos nas ementas dos cursos de graduação. Discutir/dissertar sobre os conteúdos de matemática apresenta-se como uma tarefa prazerosa depois dos vários anos de estudo abrangendo tópicos mais aprofundados e a atividade acaba por ser um repensar destes conhecimentos. Entretanto, outros aspectos do ensino requerem maior atenção. 
A percepção de como um estudante universitário interpreta hoje seus deveres e obrigações difere de outras gerações, sendo a disciplina um dos maiores problemas, disciplina não só no sentido comportamental, mas como “[...] dedicação metódica à capacidade de estudo, da realização de uma tarefa" (CORTELLA, 2014, p. 91). Isto em grande parte se deve ao afrouxamento de valores que estão na base da estrutura familiar.

Cortella coloca que:

\begin{abstract}
A sociedade ocidental atravessa hoje uma forte crise em alguns valores essenciais; há abalos cotidianos nos territórios da fraternidade, integridade e solidariedade. A perda do vigor de qualquer valor é negativa e, entre nós, ela surge toda vez em que há uma materialização excessiva da vida, uma perda de sentido da noção de coletividade e a exaltação de um egonarcisismo complacente. (CORTELLA, 2014, p. 89).
\end{abstract}

Estas mudanças de valores transparecem na escolarização e no processo educacional dos jovens e, enquanto docente atuante no ensino superior, me deparo com alunos cada vez mais despreparados para a 'vida acadêmica', com poucos conhecimentos gerais, especialmente aqueles que concernem a matemática apresentada no ensino fundamental e médio.

Esta discrepância entre a base conceitual que estamos preparados para ensinar e o conhecimento advindo dos alunos é o primeiro e grande entrave que surge no dia a dia da profissão. Aqui nasce um dos primeiros questionamentos: Como cumprir a ementa das disciplinas e, ao mesmo tempo, recuperar (ou fornecer) bases conceituais com as quais os acadêmicos já deveriam estar familiarizados?

Há de se tomar o cuidado para integrar este acadêmico no ambiente universitário para que ele não paire num 'limbo institucional', ou seja, desamparado pela escola que lhe conferiu um diploma de conclusão do ensino médio e excluído da universidade que não o acolhe pela insuficiência de seu conhecimento.

Percebemos que o sistema educacional básico está enfrentando sérias dificuldades, tanto em nível de concepções quanto a nível estrutural. A maioria das escolas possuem salas superlotadas e não contam com espaço físico para manutenção de projetos no contra turno, a indisciplina presente nas salas de aula nutre a violência entre alunos e contra o professor, estudos direcionados para avaliações externas (vestibular, ENEM, Pisa, provinha Brasil, olimpíadas de matemática, de português, etc.) estimulam a memorização de informações e a falta de professores especializados coloca em salas profissionais despreparados. Todo este cenário, juntamente com plano de carreira e remunerações aquém das solicitações da classe 
docente, aumentam o desprestígio desta profissão e, consequentemente, afasta jovens promissores desta área de atuação.

Assim, pelos motivos expostos acima, poucos estudantes optam por cursos de licenciatura e a concorrência nos vestibulares ou no Sistema de Seleção Unificado - Sisu é muito baixa ${ }^{1}$. Isto acaba permitindo que os alunos menos preparados/qualificados ingressem nestas vagas, refletindo diretamente na estruturação das licenciaturas.

Como consequência, percebi que só o conhecimento de conteúdos de matemática superior não se mostrava suficiente para garantir o aprendizado dos acadêmicos. A sala de aula pede mais disciplina, as instâncias superiores pedem menos reprovações e os métodos tradicionais acabam por excluir muitos ingressantes. Surge, então, a necessidade de repensar a prática e a própria grade curricular do curso, refletindo, entre outras coisas, sobre o tipo de profissional que se espera formar. Neste sentido, corroborando com as ideias de Ponte (2004, p. 2),

os professores universitários estão em posição privilegiada para investigar a sua própria prática. $\mathrm{Na}$ sua maioria, tendo feito doutoramento ou mestrado, têm treino como investigadores, têm a investigação entre suas funções profissionais e defrontam-se na sua prática com numerosos problemas (insucesso dos alunos, objectivos não atingidos, currículos ultrapassados, condições de trabalho inadequadas).

Por tratar-se de um curso de licenciatura em matemática, acredito que cabe a todos os envolvidos com tais atividades desenvolverem seus trabalhos de forma a preparar os acadêmicos para a docência. Logo, independente da disciplina trabalhada, o objeto final é o licenciado.

Dessa forma, é necessário ponderar sobre os critérios de avaliação, a ordem da apresentação dos conteúdos, buscar outras metodologias de ensino-aprendizagem. Muitas vezes, pela vontade de aprofundar o conhecimento matemático, enfatizamos um conteúdo de nível mais elevado sem, necessariamente, ter certeza de que o aluno está preparado para isto. No atual cenário dos cursos de graduação devemos nos lembrar de que para aprender a multiplicar é preciso (e preferível) antes saber somar, ou seja, ter o cuidado em retomar conceitualizações básicas para que o acadêmico possa prosseguir seus estudos sem lacunas naquele que será, de fato, seu objeto de trabalho: a matemática básica.

Além disso, como coloca Cyrino (2006, p. 85):

\footnotetext{
${ }^{1}$ Para constatar tais fatos basta realizar um comparativo do número de candidatos por vaga entre os cursos de licenciatura e os demais.
} 
A matemática não pode ser vista simplesmente como instrumento ou ferramenta. Compreender essas relações [entre a matemática e outras áreas do conhecimento no desenvolvimento da humanidade] pode ajudar-nos a assumir a solidariedade como forma de conhecimento e reconhecer o outro como produtor de conhecimento: como igual (sempre que a diferença lhe acarrete a inferioridade) e como diferente (sempre que a igualdade lhe ponha em risco a identidade).

Todas estas dificuldades, que extrapolam o conhecimento matemático, conduzem a busca por melhores estratégias de ensino e em formas de acolher estes estudantes, auxiliandoos a permanecerem e concluírem seu curso. A resposta para estas inquietações pode ser encontrada, em muitos casos, na parceria de trabalho que envolve ambas as áreas: a Matemática e a Educação Matemática, através do trabalho colaborativo de seus docentes, entendendo que:

Na colaboração todos trabalham conjuntamente e se apoiam mutuamente, visando atingir objetivos comuns negociados pelo coletivo do grupo. [...] as relações, portanto, tendem a ser não hierárquicas, havendo liderança compartilhada, confiança mútua e co-responsabilidade pela condução das ações. (FIORENTINI; LORENZATO, 2006, p. 115).

Portanto, o docente que ministra disciplinas de formação técnica deve, também, repensar o modo como trabalha determinados conteúdos, reforçando, sempre que possível, os aspectos da disciplina que auxiliam na formação do futuro professor, privilegiando atividades que contribuem tanto em conteúdo como na constituição do caráter deste educador. E, sempre que julgar conveniente, uma maneira de introduzir conteúdos matemáticos mais avançados é apresentar esta matemática (mais intricada) na forma de projetos de iniciação científica ou projetos de ensino. Logo, os acadêmicos interessados teriam a possibilidade de desenvolver um estudo dirigido para a descoberta de um novo resultado - ou de uma nova compreensão de um resultado.

\section{Conclusão}

O artigo, por sua caracterização metodológica como uma investigação da própria prática, apresenta apontamentos que permitiriam estabelecer averiguações mais detalhadas, mas que devido à caracterização deste texto, não serão realizadas nesta ocasião.

Ainda, as argumentações acima nos fazem refletir, constantemente, sobre o perfil de profissional que desejamos para o curso de licenciatura em Matemática, não o profissional que eu enquanto docente de Matemática Pura desejo, mas o profissional que a sociedade necessita: um profissional habilitado para trabalhar com adolescentes e crianças, para ensinar no ensino básico.

Esta não é uma tarefa fácil, pois conforme Lorenzato (2010, p. 3): 
Dar aulas é diferente de ensinar. Ensinar é dar condições para que o aluno construa seu próprio conhecimento. Vale salientar a concepção de que há ensino somente quando, em decorrência dele, houver aprendizagem. Note que é possível dar aula sem conhecer, entretanto não é possível ensinar sem conhecer. Mas conhecer o quê? Tanto o conteúdo (matemática) como o modo de ensinar (didática); e ainda sabemos que ambos não são suficientes para uma aprendizagem significativa.

Vê-se, com isso, que o ato de ensinar pode extrapolar as metodologias utilizadas, mas uma sólida preparação facilita tanto a retomada do pensamento como a variação do discurso sobre o conteúdo abordado de forma a promover os esclarecimentos pendentes. Ademais, a matemática possui características próprias e cabe ao professor reconhecer, também, que além do trabalho de formalização de conceitos pautados em materiais concretos ou questões cotidianas,

a preocupação exclusiva da matemática vista sob a ótica pragmática pode atropelar a compreensão de conceitos matemáticos que, muitos deles, surgiram apenas de estruturas. Mesmo aqueles conceitos que surgiram de motivações práticas, em algum momento precisam ser efetivados via alguma estrutura consistente. (MAGOSSI; POLETTI, 2012, p.10).

Também, segundo Brandemberg (2010, p. 133) "é através da notação matemática que ideias complexas ou mesmo processos mentais, podem ser nomeados e, assim, representados fisicamente. Podendo dessa forma, serem refletidos ou manipulados para gerar novas ideias (e suas representações)".

Assim, devemos contribuir para formar um licenciando que possua todos os conhecimentos matemáticos necessários para ser um bom profissional, mas que também saiba usufruir deste conhecimento para ensinar de forma clara e segura, superando as adversidades da profissão.

O melhor caminho para atingir tais objetivos é o trabalho colaborativo entre as grandes áreas balizadoras da licenciatura: a Educação Matemática e a Matemática, pois

\begin{abstract}
a colaboração constitui um modo de trabalho especialmente indicado para lidar com problemas de grande complexidade, demasiados pesados para serem enfrentados com êxito por uma só pessoa. Ela permite enquadrar num esforço actores com conhecimentos e competências diversas que, isoladamente, seriam impotentes para lidar com um dado problema em toda a sua dimensão, mas que em conjunto podem conseguir as soluções pretendidas. (PONTE, 2004, p. 22).
\end{abstract}

Deste modo, neste momento, não poderia deixar de citar o Grupo de Pesquisa XXXXXXXXXXX, campus XXXXXXXX, do qual faço parte e com o qual aprendi muito. As discussões realizadas no grupo foram de fundamental importância para a abertura e investigação de outras linhas de pensamento, ou seja, refletir sobre a formação do professor de matemática e como minha experiência acadêmica pode contribuir para formar um 
profissional capaz de enfrentar os desafios de sua profissão. Com isto, em conjunto com integrantes do grupo de pesquisa, desenvolvemos vários projetos de extensão voltados para os diferentes níveis de ensino, desde a alfabetização matemática $\left(1^{\circ}\right.$ ao $5^{\circ}$ ano), perfazendo o ensino fundamental e médio, até cursos oferecidos aos professores já em exercício.

Estas ações contribuíram para idealizar o professor de matemática que precisamos formar: um profissional que conhece com propriedade o conteúdo matemático que irá trabalhar e que consiga fazer uso de diferentes estratégias de ensino para garantir uma aprendizagem matemática de qualidade. Para isto, percebi que só o trabalho com os conteúdos técnicos não bastam, logo surge à preocupação de rever as atitudes em sala, pois muito do que nos define como professor advém de exemplos vivenciados. Assim, acredito que a postura que assumimos no trato da matemática acadêmica irá refletir no modo como o acadêmico trabalhará a matemática escolar, pois a formação educacional é um processo complexo e não se resume a mera aquisição de conhecimentos, mas as ações que efetivamos pautados nestes conhecimentos.

Por fim, o desejo de pesquisar matemática continua, ou seja, a vontade de explorar mais deste universo maravilhoso se mantém e, acredito que, é justamente esta vontade aliada a preocupação com a formação do licenciando que deve ser transmitida aos graduandos, para que eles trabalhem e defendam com entusiasmo sua área de atuação, despertando nos seus futuros alunos um interesse crescente e genuíno por esta ciência, ensinando e se fazendo entender.

\section{Referências}

ÁVILA, Geraldo. Análise Matemática para licenciatura. 3 ed. São Paulo: Edgar Blücher, 2006.

BEILLEROT, Jacky. A pesquisa: esboço de uma análise. In: ANDRÉ, M. (Org.). O papel da pesquisa na formação e prática dos professores. Campinas: Papirus, 2011, p. 71-90.

BRANDEMBERG, João Cláudio. Uma análise histórico-epistemológica do conceito de grupo. São Paulo: Livraria da Física, 2010.

CORTELLA, Mario Sergio. Educação, Escola e Docência: novos tempos, novas atitudes. São Paulo: Cortez, 2014.

CYRINO, Márcia Cristina de Costa Trindade. Preparação e Emancipação Profissional na Formação Inicial do Professor de Matemática. In: NARACATO, Adair Mendes; PAIVA, Maria Auxiliadora Vilela (Org.). A formação do Professor que Ensina Matemática: perspectivas e pesquisas. Belo Horizonte: Autêntica, 2006. p.77-88.

EUCLIDES. Os Elementos. Tradução e Introdução de Irineu Bicudo. São Paulo: Editora UNESP, 2009. 
FERREIRA, Jamil. A Construção dos Números. Rio de Janeiro: SBM, 2010.

FIORENTINI, Dario; LORENZATO, Sergio. Investigação em Educação Matemática: percursos teóricos e metodológicos. Campinas: Autores Associados, 2006.

LORENZATO, Sergio. Para Aprender Matemática. 3. ed. Campinas: Autores Associados, 2010. MAGOSSI, José Carlos; POLETTI, Elaine Cristina Catapani. O Movimento das Estruturas Matemáticas. Revista Brasileira de História da Matemática, vol. 12, n. 25, p. 1-14, ago.-dez., 2012.

MORAIS FILHO, Daniel Cordeiro de. Um Convite a Matemática: fundamentos lógicos com técnicas de demonstração, notas históricas e curiosidades. 2 ed. Campina Grande: EDUFCG, 2007.

MOREIRA, Plínio Cavalcanti; DAVID, Maria Manuela M. S.. A Formação Matemática do Professor: licenciatura e prática escolar. Belo Horizonte: Autêntica, 2005.

PONTE, João Pedro. Investigar a nossa própria prática: uma estratégia de formação e de construção do conhecimento profissional. In: CASTRO, E.; TORRES, E. (Orgs.) Investigación em educación matemática. Coruna: Universidade de Coruna, 2004. p.61-84. 